\title{
GRUNDLAGEN DER PHILOSOPHIE
}

VON

\section{ÁKOS VON PAULER}

O. Ö. PROFESSOR DER PHILOSOPHIE

AN DER UNIVERSITĀT BUDAPEST

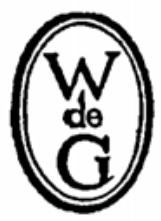

BERLIN UND LEIPZIG 1925

WALTER DE GRUYTER \& CO.

VORMALS G. J. GÖSCHEN'SCHE VERLAGSHANDLUNG / J. GUTTENTAG, VERLAGSBUCHHANDLUNG / GEORG REIMER / KARL J. TRÜBNER / VEIT \& COMP. 
Alle Rechte, einschließlich das der Übersetzung, vorbehalten. 